\section{Preoperative MRI to plan infrapatellar fat pad resection during total knee arthroplasty}

We thank Pan et al for their initial paper ${ }^{1}$ and subsequent response to our comment. ${ }^{2-4}$ We agree with the proposed biphasic role of the infrapatellar fat pad (IPFP). Although there is evidence to support a change of practice towards preservation of the IPFP, ${ }^{5}$ we agree that there should not be a 'one shoe fits all approach', there being cases in which benefit may be derived from IPFP resection.

A considered approach offered by Han et $a l^{4}$ involves using screening MRIs to identify IPFP signal intensity alterations and a subsequent indication for resection. However, this technique is not yet validated with high-quality randomised controlled trials (RCTs). ${ }^{4}$ An alternative solution proposed by Sekiya et $a l^{6}$ may be the use of postarthroplasty arthroscopic IPFP debridement.

Currently the incidence of knee pain post total knee arthroplasty (TKA) is low, with approximately $10 \%$ of patients reporting mild to moderate pain ${ }^{7} 8$ and $4.8 \%$ reporting severe pain. ${ }^{6}$ The study by Sekiya et $a l^{6}$ found that of the $4.8 \%$ of patients with severe knee pain, a significant proportion had scar tissue between the IPFP and the tibiofemoral space, impinging the femorotibial joint. Following arthroscopic resection of this scar tissue, $63 \%$ of the patients reporting severe pain were now pain free and a further $23 \%$ had their pain at least halved. ${ }^{6}$

This suggests that less than $2 \%$ of patients will report severe knee pain post TKA if the IPFP is preserved and arthroscopic debridement is performed as required. However, IPFP screening as proposed by Han et al has the potential to reduce reoperation and perhaps reduce morbidity beyond this. Consequently, we eagerly await RCTs investigating its use and the possibility of reducing severe pain post TKA to less than $1 \%$.

Matthew J Binks, R Vlok, R Holyoak, T Melhuish, L White

Wagga Wagga Rural Referral Hospital, Wagga Wagga, New South Wales, Australia
Correspondence to Dr Matthew J Binks, Wagga Wagga Rural Referral Hospital, Corner Sturt Hwy \& Docker St, Wagga Wagga, NSW 2650, Australia; mattbinks00@ gmail.com

Citation: Han W, Pan F, Liu Z, et al. Response to: 'The role of infrapatellar fat pad resection in total knee arthroplasty' by White et al. Ann Rheum Dis 2016;75:e67.

Competing interests None declared.

Provenance and peer review Not commissioned; internally peer reviewed.

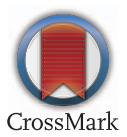

To cite Binks MJ, Vlok R, Holyoak R, et al. Ann Rheum Dis 2017;76:e34.

Accepted 3 January 2017

Published Online First 23 January 2017

Ann Rheum Dis 2017;76:e34. doi:10.1136/annrheumdis-2017-211079

\section{REFERENCES}

1 Pan $F$, Han W, Wang $X$, et al. A longitudinal study of the association between infrapatellar fat pad maximal area and changes in knee symptoms and structure in older adults. Ann Rheum Dis 2015;74:1818-24.

2 White LD, Melhuish TM. The role of infrapatellar fat pad resection in total knee arthroplasty. Ann Rheum Dis 2016;75:e66.

3 Bai HX, Lee AM, Wang Z, et al. Infrapatellar fat pad maximal area and changes in knee symptoms: gender-related difference or gender difference in reporting? Ann Rheum Dis 2016;75:e3.

4 Han W, Pan F, Liu Z, et al. Response to: 'The role of infrapatellar fat pad resection in total knee arthroplasty ' by White et. al. Ann Rheum Dis 2016;75:e67.

5 White L, Holyoak R, Sant J, et al. The effect of infrapatellar fat pad resection on outcomes post-total knee arthroplasty: a systematic review. Arch Orthop Trauma Surg 2016;136:701-8

6 Sekiya $\mathrm{H}$, Takatoku K, Takada $\mathrm{H}$, et al. Painful knee after total knee arthroplasty is not a frequent complication and could be treated by arthroscopic debridement. Bone Joint J 2016;98-B(Supp 3):152.

7 White L, Hartnell N, Hennessy M, et al. The impact of an intact infrapatellar fat pad on outcomes after total knee arthroplasty. Adv Orthop Surg 2015;2015:1-6.

8 White L, Stockwell T, Hartnell N, et al. Factors preventing kneeling in a group of pre-educated patients post total knee arthroplasty. J Orthop Traumatol 2016:17:333-8 